\title{
Lojistik 4.0 Kavramına Genel Bir Bakış: Geçmișten Bugüne Gelişim ve Değişimi ${ }^{1}$
}

\author{
Ümit YILMAZ ${ }^{2} \&$ Bülent DUMAN ${ }^{3}$
}

\begin{abstract}
Özet
Dördüncü sanayi devrimi olarak lanse edilen Endüstri 4.0 kavramı, günümüzde birçok sektörü etkisi altına alacak önemli bir potansiyele sahiptir. Endüstri 4.0'1n etkisi altında kalan sektörlerin başında gelen lojistik sektöründen talep edilen hizmet türleri de, endüstriyel süreçlerin dijitalleşmesiyle çeşitlenmektedir. Lojistik sektöründeki tüm Endüstri 4.0 uygulamaları temelde Lojistik 4.0 alanına girmektedir. Bu çalışmanın amacı, kavramsal bir araştırmayla Lojistik 4.0'ın geçmişten günümüze gelişimini ve günümüzdeki mevcut durumunu mercek altına alarak ana hatlarını çizmek ve Lojistik 4.0'ın henüz keşfedilmemiş veya gelişime açık alanlarına ışık tutmaktır.
\end{abstract}

Anahtar Kelimeler: Lojistik, Lojistik 4.0, Endüstri 4.0, Lojistik Sektöründe Eğilimler, Teknolojik Gelişmeler

\section{An Overview On The Concept Of Logistics 4.0 Concept: Development And Change From Past To Present}

\begin{abstract}
Nowadays the concept of Industry 4.0, launched as the fourth industrial evolution, has an important potential to influence many sector. The service types demanded from the logistics sector, which is one of the sectors that are under the influence of Industry 4.0, are also diversified by digitalization of industrial processes. All Industry 4.0 applications in the logistics sector are basically in Logistics 4.0. The aim of this study is to draw the outline of Logistics 4.0 by reviewing development from past to present and current state, and shed light on the undiscovered or developing areas of Logistics 4.0.
\end{abstract}

Key Words: Logistics, Logistics 4.0, Industry 4.0, Trends in Logistics Sector, Technological Developments

\footnotetext{
${ }^{1}$ Bu çalışmanın bir bölümü Türkiye, Balıkesir'de 27-28 Haziran 2018 tarihleri arasında düzenlenen International Conference on Empirical Economics and Social Sciences (ICEESS'18)'te bildiri olarak sunulmuştur.

2 Öğr. Gör., Balıkesir Üniversitesi, Bigadiç Meslek Yüksekokulu, Yönetim ve Organizasyon Bölümü, umityilmaz@balikesir.edu.tr

${ }^{3}$ Öğr. Gör., Balıkesir Üniversitesi, Bigadiç Meslek Yüksekokulu, Finans, Bankacılık ve Sigortacılık Bölümü, bduman@balikesir.edu.tr
} 


\section{Giriş}

Yeni bilgi teknolojileri, dijitalleşme ve inovasyon için ideal koşulları yaratmakta ve bu da lojistik sektöründe çı̆̆ır açan değişimlere yol açmaktadır. Günümüzün popüler konularından biri de hiç şüphesiz Endüstri 4.0 kavramıdır. Endüstri 4.0 kavramının temelini ise dijitalleşme oluşturmaktadır. Dijitalleşme, tıpkı küreselleşmede olduğu gibi insan yaşamında, kurum ve kuruluşların süreçlerinde ve toplumların yapılarında kalıcı değişimlere yol açmaktadır.

Lojistik endüstrisi tedarik zincirinin her adımında yer almakta ve bu nedenle tedarik zincirinin dijital dönüşümünün başarısında önemli bir rol oynamaktadır. Her alanda rekabet içerisinde kalmak amacı ile de bu dönüşüme ayak uydurulması gerekmektedir. Özellikle lojistik şirketlerinin yerel veya küresel pazarda başarılı olabilmesi için uluslararası lojistik süreçlerinde ve değer zincirlerinde lider olması gerekir. Üçüncü parti lojistik hizmeti sağlayan şirketlerin temel amacı tedarik zinciri boyunca tedarik zinciri katılımcılarının arasında koordinasyon ve iletişimi sağlıklı bir şekilde yönetebilmektir. Dijitalleşme ile beraber tedarik ağının da dijitalleşmesi lojistik firmalarına faaliyetlerinde kolaylıklar sağlayacaktır.

Makalede, Endüstri 4.0 kavramı ile beraber anılan nesnelerin interneti, siber-fiziksel sistemler, büyük veri ve veri analitiği, bulut lojistiği, 3 boyutlu yazıcılar, artırılmış gerçeklik ve otonom robotlar kavramlarının taşımacılık, depolama ve malzeme akışı gibi lojistik faaliyetlerin dijitalleşmesindeki rolleri incelenmiştir.

\section{Endüstri 4.0 Kavramı}

Endüstri 4.0, 2011 yılında Hannover fuarında lanse edilen yeni sanayi devrimidir. Endüstri 4.0 herhangi bir nitelik gerektirmeyen işlerin kol gücü yerine makine ve robot gücünün kullanılmasına ve nitelik gerektiren işler üzerine uzmanlaşılmasına dayanan bir katma değer yaratma devrimidir (Sener ve Elevli, 2017: 26). Makinelerin, insan gücünün yerini alarak, bilgisayarlar ve internet teknolojilerindeki yeni gelişimler sayesinde koordine edilebilir hale gelerek üretim süreçlerinin kendiliğinden yönetebilir hale gelmesi Endüstri 4.0 kavramının ortaya çıkmasını sağlamıştır (Bulut ve Akçacı, 2017: 53). Endüstri 4.0, bu sayede ürünlerin ve üretim sistemlerinin yaşam döngüsünde sürekli artarak bireyselleşen müşteri isteklerine odaklanma ve fikir aşamasından başlayarak ürün geliştirme ve üretim siparişinden, bir ürünün son kullanıcıya dağıtımını ve geri dönüşümünü de kapsayacak şekilde tüm zinciri içine alan hizmetleri sağlama imkanına daha rahat sahip olacaktır (Pamuk ve Soysal, 2018: 44).

Lukac'a göre; ilk sanayi devrimi, 18. yüzy1lın sonlarında su ve buhar gücüne dayalı makinelerden oluşan üretim tesisleriyle temsil edilmektedir. İkinci sanayi devrimi ise 20. yüzyılın başında elektrik enerjisine dayalı kitlesel üretim ile gösterilmektedir. Üçüncü sanayi devrimi, 1970’li yılların henüz başında elektronik ve bilgi teknolojilerine dayalı otomatik üretim ile temsil edilmektedir. Ve son olarak dördüncü sanayi devrimi olan Endüstri 4.0, heterojen verilere ve bilgi entegrasyonuna dayanan siber fiziksel sistemlerle üretim ile gösterilmektedir (Lu, 2017: 1). 2030 yılından itibaren ise 
dijital ekosistemin, Endüstri 4.0 kavramının yerini alacağı rivayet edilmektedir. Bahsi geçen dijital ekosistem kavramı; doğal ekosistemlerden esinlenen, kendi kendini düzenleme, ölçekleyebilme ve sürdürülebilir olma niteliğine sahip, ayrıştırılabilir, uyarlanabilir ve dış dünya ile etkileşime açık sosyoteknik bir sistemdir (Ostadzadeh, Shams and Badie, 2015: 513). Endüstri 1.0'dan dijital ekosisteme olan evrelere dair bilgiler Şekil 1'de özetlenmiştir (Schrauf and Berttram, 2016: 8).

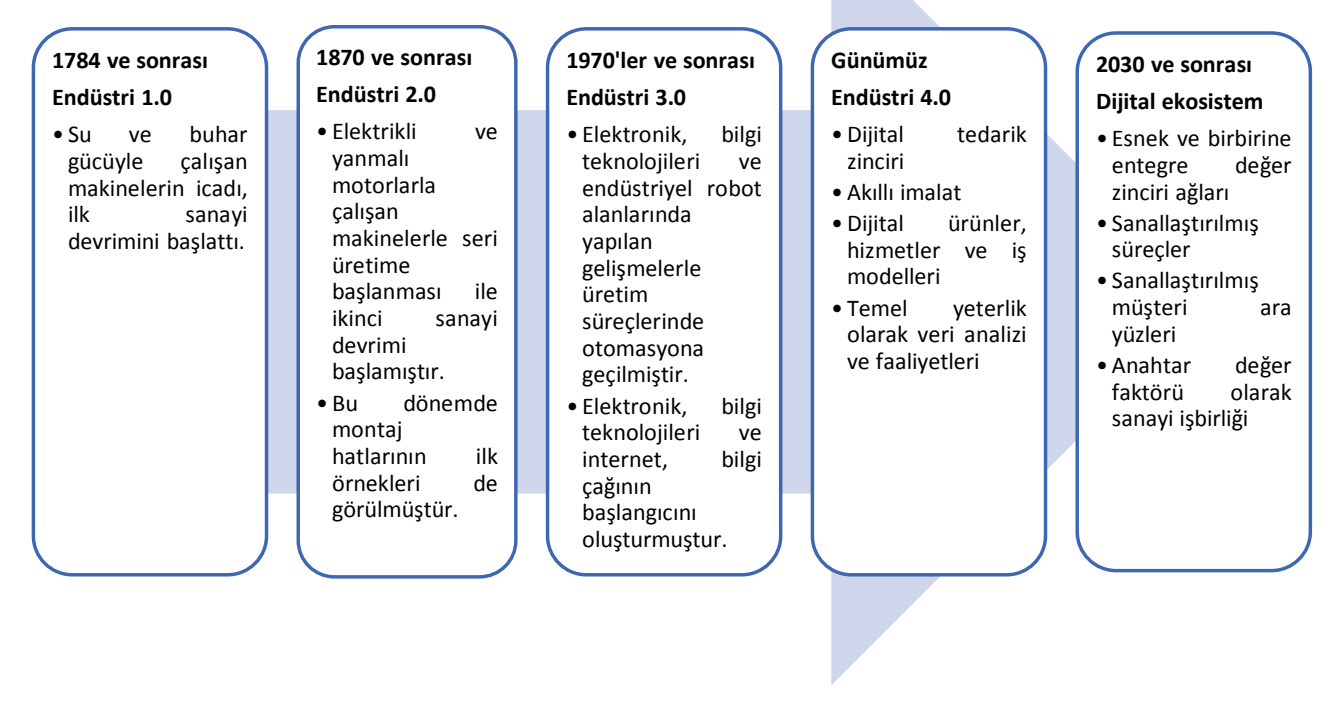

Şekil 1. Endüstri 4.0’a giden yol ve geleceğe dair beklentiler

Dünya çapındaki birçok hükümetler, Endüstri 4.0 kavramının sağlayacağı faydalardan azami düzeyde faydalanabilmek için bir dizi kararlar almıştır. Bu kararlar aşağıdaki gibidir (AB Bakanlığı, 05.06.2018; Liao, Deschamps, Loures and Ramos, 2017: 3609-3610; Işık, 2016: 19):

- 2011 y1lında, Amerika Birleşik Devletleri Hükümeti, ülkeyi gelecek nesil imalata yönlendirmek için “İleri İmalat Ortaklığı” olarak adlandırılan ulusal düzeyde tartışma, faaliyet ve öneri serileri başlatmıştır.

- 2012 y1lında, Alman Hükümeti, ileri teknolojilerin geliştirilmesi için y1llık bir milyon Euro bütçe ayrılan "Yüksek Teknoloji Stratejisi 2020" eylem planını kabul etmiştir.

- 2013 yılında, Fransız Hükümeti, “La Nouvelle France Industrielle” olarak adlandırılan, 34 sektörü temel alan ve Fransa'nın endüstri politikası öncelikleri olarak ifade edilen bir stratejik araştırma başlatmıştır.

- 2013 yılında Birleşik Krallık hükümeti, "İmalatın Geleceği” olarak adlandırılan, 2050 yılına kadar imalat sektörü için uzun vadeli bir görünüm sunmuştur. Bu eylem planı ile önümüzdeki on yıllarda Birleşik Krallık imalatının büyümesine ve esnek hale gelmesine yardımcı olmak için dengelenmiş ve odaklanılmış bir politika sağlamak amaçlanmıştır.

- 2014 yılında, Güney Kore Hükümeti, Güney Kore imalatının yeni bir atılımı için dört strateji ve kararın önemini belirten "İmalatta İnovasyon 3.0'1" ilan etmiştir. 
- 2015 yılında, Türkiye Hükümeti, “64. Hükümet Programı ve Eylem Planı” ile 25 öncelikli dönüşüm programıyla Türkiye'ye nitelik sıçraması yaşatmak amaçlanılmıştır. Öte yandan, Bilim, Sanayi ve Teknoloji Bakanlı̆̆ı'nın Türkiye Sanayi Stratejisi Belgesi (2015-2018), Verimlilik Stratejisi ve Eylem Planı (2015-2018) ve Türkiye Yazılım Sektörü Stratejisi ve Eylem Planı (20172019) belgelerinde sanayinin dijital dönüşümüne yapılan atıflar dikkat çekmektedir.

- $\quad 2015$ yılında, Çin Hükümeti, "İnternet Plus" planının yanı sıra "Made in China 2025" stratejisini bildirmiştir. Bu strateji, Çin'deki bilişim ve sanayileşmeyi hızlandırmak için imalat sektöründeki 10 alana öncelik tanımaktadır.

- 2015 y1lında, Japon Hükümeti, kendilerinin dünyaya yön veren "Süper Ak1llı Toplum” hedeflerini gerçekleştirmek için imalat sektörüne özel dikkatin verildiği "5. Bilim ve Teknoloji Temel Planı"”nı kabul etmiştir.

Genel olarak, Endüstri 4.0'ın ana amacı, akıllı şebeke, hareketlilik, endüstriyel operasyonların esnekliği ve birlikte çalışabilirliği, müşteriler ve tedarikçiler ile entegrasyon ve yenilikçi iş modellerinin benimsenmesi anlamına gelen ve "akıllı fabrika" olarak da adlandırılan dijital imalatın sürdürülebilir hale getirilmesidir. Dördüncü sanayi devrimi ile ilişkili tamamlayıcı özellik, siber-fiziksel sistemlere dayanan akı1lı şebekelerdir (Barreto, Amaral and Pereira, 2017: 1247). Endüstri 4.0 için merkezi öneme sahip olan durum; akıllı hareketlilik, ak1llı şebeke, ak1lı lojistik, akıllı binalar ve akıllı evler ve diğer akıllı altyapı sistemi ara yüzlerinin birbirleriyle ortak yönde hareket etmeleridir. Bunun yanı sira hem iş, hem de sosyal ağlara olan bağlantılar, dijital dönüşümde giderek daha önemli bir rol oynamaktadır. Nesneler arası internet, hizmetler, veriler ve insanlar içinde sunulan bu ara yüzler ve ağlar, imalat anlamında çok büyük değişikliklere yol açacak şekilde tasarlanmıştır. Bu ara yüzler ve bağlantıların akıllı fabrika çatısı altındaki görünümü Şekil 2.'de gösterilmiştir (Schlaepfer and Koch, 2015: 4).

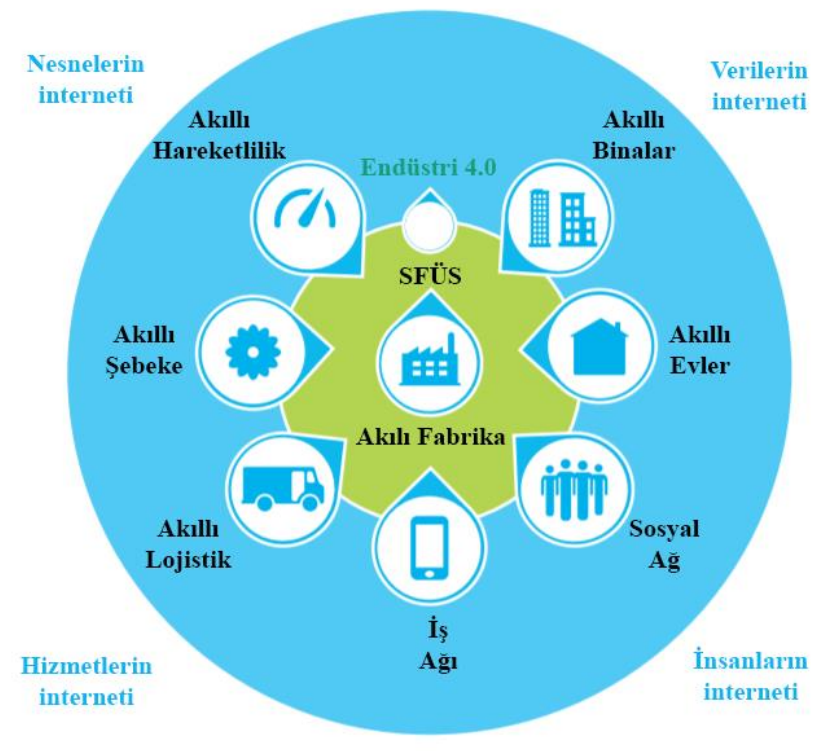

Şekil 2. Endüstri 4.0 çevresi 
Uluslararası Taşımacılık ve Lojistik Hizmet Üretenleri Derneği (UTIKKAD) Genel Müdürü Cavit Uğur'a göre Endüstri 4.0'ın lojistik sektöründe özellikle iş yapma süreçlerini yeniden belirleyeceği mutlaktır. Endüstri 4.0 lojistiğin 7 doğrusu olarak bilinen doğru ürünün, doğru miktarda, doğru biçimde, doğru zamanda, doğru kaynaktan doğru yolla ve doğru fiyatla sağlanması süreçlerinin tamamını etkileyecek ve yeniden şekillendirecektir. Bunun temel nedeni Endüstri 4.0 yaklaşımının bu süreçlerin birbirleriyle gerçek zamanlı iletişim halinde olması esasına dayanmasıdır (Özdemir ve Özgüner, 2018: 42). Yapılan çalışmada akıllı fabrikaların bir alt sistemi olan akıllı lojistik kavramı ve lojistik alanındaki gelişmeler ve değişmeler incelenmiş̧ir.

\section{Lojistik 4.0 Kavramı}

Almanya'da ortaya çıkmasının ardından tüm dünyada hızla yayılan dördüncü sanayi devrimi kavramı, rekabetin ön planda olduğu tüm diğer sektörler gibi lojistik sektöründe de hızlı bir şekilde önemli duruma gelmiştir (Saatçioğlu, Tuğdemir Kök ve Özispa, 2018:1684). Lojistik sektörünün, neredeyse diğer tüm üretim ve hizmet sektörü ile yakın ilişki içerisinde olması, endüstride olası değişimlere adapte olması gerekliliğini beraberinde getirmektedir. Lojistik süreçlerin tamamen fiziksel olarak ele alınması, lojistik hizmet sağlayıcılarının rekabetçi olabilmeleri için yeterli değildir. Geleceğin lojistik adımları dijitalleşme, akıllı çözümler ve otomasyona dayalı atılacaktır. Lojistik hizmet sağlayıcıları için başarının anahtarı geçmişte verimlilik, standardizasyon ve düşük maliyetti. Dijitalleşme ile beraber bunlara çeviklik, müşteri odakl1lık, esneklik ve sürekli inovasyon gibi zorunluluklar eklenmiştir.

Dördüncü sanayi devrimi ile lojistik sektörü dijital dönüşümden nasibini almıştır. Lojistik süreçlerinin dijitalleştirilmesi günümüzde bir standart haline gelmektedir. Günümüzde bu gelişmeyi dikkate almayan şirketler rekabette geride kalacaklardır. Aksine, dijitalleşmeyi iyileştirme fırsatı olarak kabul eden şirketlere ise belirleyici bir rekabet avantajları sağlayacaktır (Jeschke, 05.06.2018). Geniş anlamda Lojistik 4.0, lojistik alanında dijitalleşmenin ve otomasyonun nasıl şekillendirilmesi ve desteklenmesi gerektiğini ve Endüstri 4.0'1n taşımacılık ve çapraz-fonksiyonel koordinasyon görevleri üzerindeki etkilerini açıklar (Scherf, 05.06.2018). Dar anlamda ise Lojistik 4.0, üreticiden üçüncü parti lojistik firmaları aracılığıyla müşterilere kadar tedarik zincirindeki tüm firmaların, yüksek bağlantılı süreçlerinin, verilerinin ve sistemlerinin bütünleştirilmesini ve entegrasyonu olarak tanımlanabilir (Schiemann, 2016: 7). Bu sayede, tedarik zincirindeki tüm paydaşların etkinlik ve verimliliğini artıracak, lojistik süreçlerini daha esnek ve ekonomik hale getirecektir. Bu kavram, tedarik zincirinde faaliyet gösteren tüm şirketlerin işbirliği sonucu elde edecekleri optimal kazancın, şirketlerin kendi başlarına kendilerine göre ulaşabilecekleri optimal kazancın toplamını aşacağını ifade etmektedir. Endüstri 4.0 kavramı fabrikalar için ne kadar önemliyse, Lojistik 4.0 kavramı da tedarik zinciri için o kadar önemlidir. 
Lojistik 4.0'ın amac1, etkinliği (esneklik, bireyselleştirilmiş hizmetler, süreçler ve ürünler) ve verimliliği (şeffaflık, süreç hızı, hata azaltma ve birleştirme) ve tedarik zinciri ortaklarını (toptancılar, perakendeciler, lojistik hizmet sağlayıcıları ve müşteriler) iyileştirmek ve bilgi iletişim teknolojilerini merkezi olmayan karar verme yapılarıyla artırmaktır (Czaja, 2016: 6-7). Bilgi teknoloji sistemleri tedarik zincirinin merkezi olmayan yönetimini aşağıdaki adımlarla kontrol etmeye yardımcı olur (Akinlar, 05.06.2018):

- Şeffaflık yaratmak için tedarik zincirinin ve süreçlerinin kavranması ve değerlendirilmesi: $\mathrm{Bu}$ kavrama ve değerlendirme işleminin gerçekleştirebilmesi için planlama sonuçlarının ve olayların birbirleri ile karşılaştırılması gerekir.

- $\quad$ Aktif, hedef odaklı ve güvenli bir eylem ve tepkilerin gerçek zamanlı olarak alınabilmesi için karar desteğinin verilmesi: Senaryo bazlı planlama için optimizasyon ve simülasyon modellerinin birbirleri ile entegrasyonu gerekir.

- $\quad$ Kişiye ve kuruma özel planlama ve kontrol fonksiyonlu planların uygulanması.

Lojistik 4.0'ın odak noktası, tahmine dayalı tedarik zinciri yönetimi gibi yeni ve yenilikçi teknolojilerin kullanımı üzerinedir. Teslimat güvenilirliği, teslimat kalitesi, teslimat esnekliği, teslimat yeteneği ve hizmet düzeyi gibi performans kriterleri bu yeni ve yenilikçi teknolojilerin kullanımı ile optimize edilebilir. Lojistik 4.0'a ilişkin hedeflenen performans kriterlerine erişmek için lojistik süreçlerdeki bilgi ve malzeme akışını hem ileri hem de tersine doğru bir şekilde planlamak, uygulamak, kontrol etmek ve geri besleme ile düzeltme işlemi yapmak gerekmektedir.

Dijitalleşme ve otomasyon çağına ayak uyduran şirketler, lojistik süreçlerde hataları ve maliyetleri minimize ederek ve müşteri memnuniyetini maksimize ederek önemli bir rekabet avantaj1 elde edebilirler. Lojistik 4.0’’n şirketlere sağladığı faydalar aşağıdaki gibidir (Scherf, 05.06.2018):

- Veri kalitesinin artması: Verilerin toplanması ve işlenmesi, ağ sistemlerinde en önemli fonksiyonel konulardan biridir. Sadece ürüne özgü ana verileri elde bulundurmaktan ziyade, bunun yanı sıra ürünler arasındaki ilişkilerin değerlendirilmesi de önemlidir. Dijitalleşme çağında veri kalitesi, diğer şirketler için çekici bir ortak olarak nitelendirmek için önemli bir ön koşuldur.

- Hammadde ve yardımc1 malzemelerin daha iyi fiyata tedarik edilmesi: Uluslararası bir iletişim ağına sahip olan şirketler, fiyat teklifi almak için daha geniş bir tedarik ağına sahiptirler. $\mathrm{Bu}$ sayede şirketler hem uluslararası alanda uygun fiyatta ürün tedarik edebilmekte, hem de faaliyet gösterdiği pazarda pazarlık konusunda elini güçlendirmektedir.

- Dünya çapında kaynak temin edilebilmesi: Küresel ağlara erişim sayesinde şirketler yalnızca yerli kaynaklardan tedarik yapmamaktadır. Küresel kaynaklar, küçük ve orta büyüklükteki şirketlerin de tüm dünyadaki hammaddelere ve yardımcı malzemelere erişimine olanak verir. 
- $\quad$ Yeni satış kanallarına sahip olunması: Şirketlerin kurumsal teklifleri, uluslararası ağlar yardımıyla tüm dünyadaki ilgili taraflara açıktır. Dijital dönüşüm, bu sayede şirketlerin yeni hedef pazarlar belirlemesine yardımcı olmaktadır.

Bunlara ek olarak; verimlilik ve performansta iyileşme ve iş gücünden tasarruf, stok yönetiminin güvenilirliği, reaktiflik etkinlik ve uyarlanabilirlik, kesintisiz ve anında iletişim, zorlu çalışma koşullarının azaltılması ve karar vermenin iyileştirilmesi de Lojistik 4.0'ın şirketlere sağladığı faydalar arasında yer almaktadır.

Lojistik sektöründe Endüstri 4.0 etkilerini görebilmek için önceki sanayi devrimleri doğru analiz edilmesi gerekmektedir (Öztemel ve Gürsev, 2018: 148). Lojistik 4.0 bir devrimden ziyade, lojistik operasyonlarında yenileşim gerçekleştirmek için itici güç olan lojistik evrimindeki bir evredir. Lojistik evriminin evreleri Şekil 3.’te belirtilmiştir. Şekilden de görüleceği üzere lojistik evriminde evre arttıkça karmaşıklık derecesi de artmaktadır.
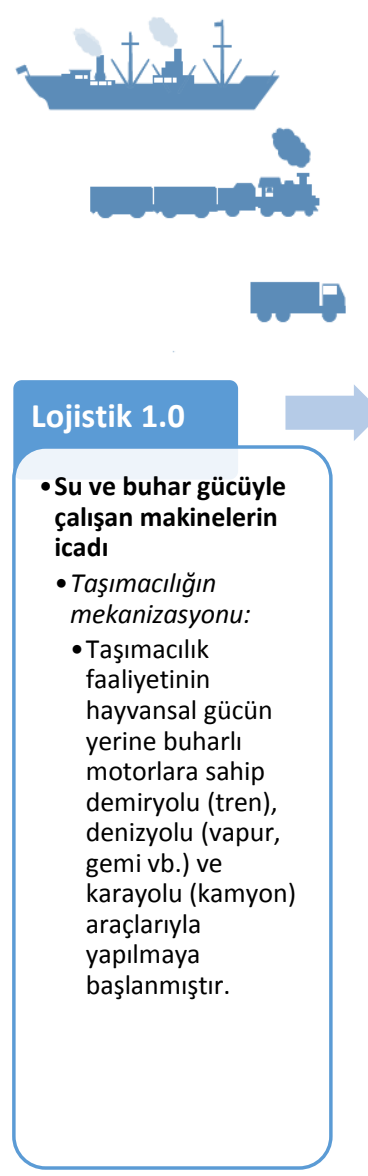
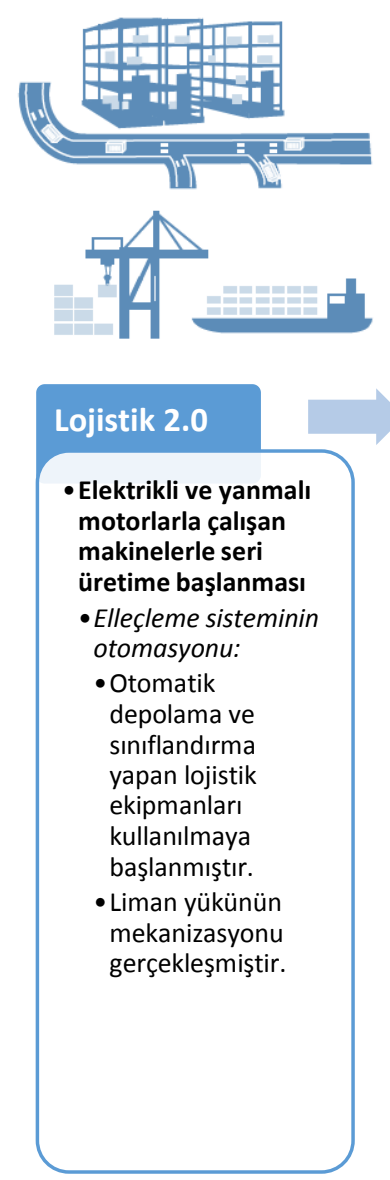
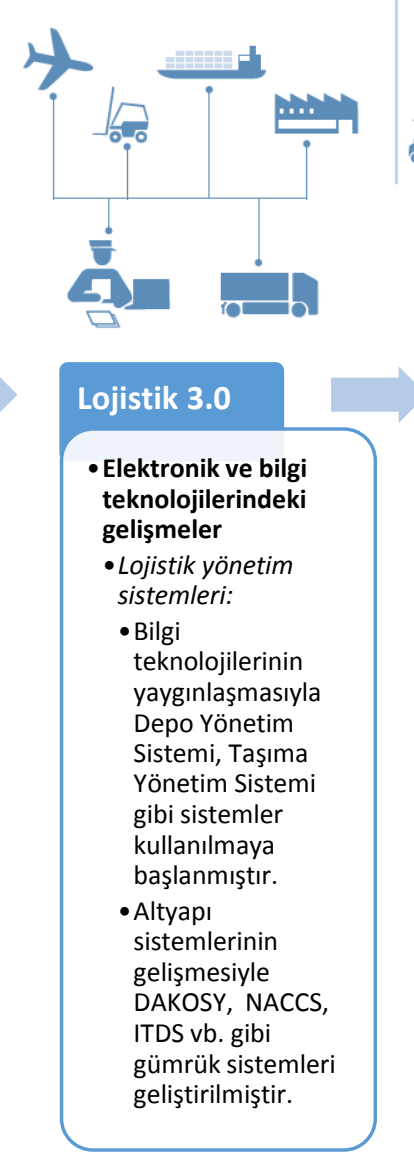

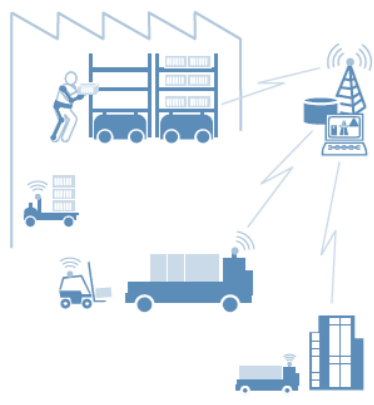

Lojistik 4.0

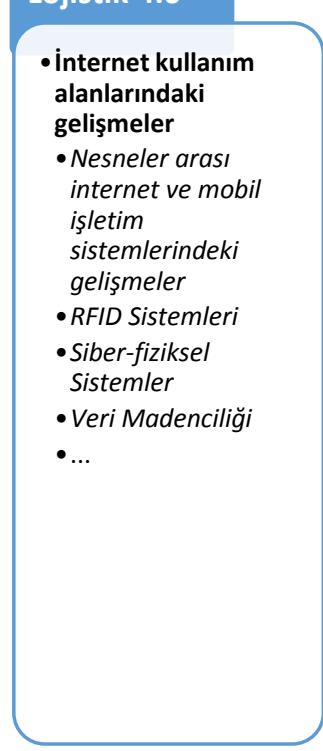

Şekil 3. Lojistik evriminin evreleri (Onuzaka, 2015:3)

Lojistik alanında, sanayi devrimlerine paralel olarak günümüze kadar dört devrimci değişiklik gerçekleşmiştir. İlk devrim, 19. yüzyılın ikinci yarısından 20. yüzyıla kadar uzanmış ve "ulaşımın 
mekanizasyonu" olarak adlandırılmıştır. Bu zaman aralığında demiryolları, denizyolları ve karayolları araçlarının kullanımı artmıştır. İkinci devrim, 1960'lı yıllarda gerçekleşmiş ve kargo elleçleme otomasyonu ile özdeşleşmiştir. Bu devrimle beraber otomatik depolama ve sınıflandırma yapan lojistik ekipmanları kullanılmaya başlanmış ve bu sayede elleçleme faaliyetlerinde kısmi mekanizasyona geçilmiştir. Üçüncü devrim ise, 1980'li yıllarda gündeme gelmiş ve "lojistik yönetiminin sistemleştirilmesi” olarak adlandırılmıştır. Bu devrimle beraber lojistik yönetiminde bilgi teknolojileri yoğun bir şekilde kullanılmaya başlanmıştır (Wang, 2016: 69). Dördüncü devrim ise günümüzde halen gerçekleşmeye devam etmekte ve lojistik süreçlerin dijitalleşmesi etrafında gelişmekte ve derinleşmektedir.

Lojistiğin gelişme evrelerinde yaşadığı devrimler Şekil 4'te detaylı olarak anlatılmıştır.

\begin{tabular}{|c|c|c|c|c|c|}
\hline \multirow{2}{*}{$\begin{array}{c}\text { Tipik } \\
\text { Planlama } \\
\text { Alanları }\end{array}$} & \multicolumn{5}{|c|}{ Lojistik'in Gelişme Seviyeleri } \\
\hline & Lojistik 1.0 & Lojistik 2.0 & Lojis & 3.0 & Lojistik 4.0 \\
\hline Ağ Tasarımı & $\begin{array}{c}\text { Yerel uygulamalı } \\
\text { yapılar }\end{array}$ & $\begin{array}{c}\text { Global } \\
\text { uygulamalı } \\
\text { yapılar }\end{array}$ & $\begin{array}{l}\text { Kismi global } \\
\text { ERP }\end{array}$ & $\begin{array}{c}\text { Tam global } \\
\text { ERP }\end{array}$ & $\begin{array}{l}\text { Açık ve esnek } \\
\text { çalışma alanı }\end{array}$ \\
\hline $\begin{array}{l}\text { Taşıma } \\
\text { Lojistiği }\end{array}$ & Merkezi olmayan & Merkezi filolar & $\begin{array}{l}\text { Tahmine } \\
\text { dayalı } \\
\text { merkezi } \\
\text { filolar }\end{array}$ & $\begin{array}{c}\text { Gerçek } \\
\text { zamanlı ve } \\
\text { navigasyon } \\
\text { bağlantılı } \\
\text { rotalama }\end{array}$ & $\begin{array}{c}\text { Otonom (özerk) } \\
\text { kamyonlar }\end{array}$ \\
\hline $\begin{array}{c}\text { Satın alma } \\
\text { Lojistiği }\end{array}$ & $\begin{array}{c}\rightarrow \\
\text { İtme teslimat } \\
\text { süreci }\end{array}$ & $\begin{array}{c}\text { Çekme teslimat } \\
\text { süreci }\end{array}$ & $\begin{array}{l}\text { Eᄐ욜 } \\
\text { Tedarikçi } \\
\text { Yönetimli } \\
\text { Envanter }\end{array}$ & $\begin{array}{l}\text { Otonom } \\
\text { (özerk) } \\
\text { envanter } \\
\text { yönetimi }\end{array}$ & $\begin{array}{l}\text { Tahmine dayalı } \\
\text { tedarik lojistiği } \\
\text { yönetimi (Büyük } \\
\text { veri) }\end{array}$ \\
\hline $\begin{array}{c}\text { Depolama } \\
\text { Lojistiği }\end{array}$ & $\begin{array}{c}\text { Otomasyonun } \\
\text { Olmaması }\end{array}$ & $\begin{array}{c}\text { Otomatik depo } \\
\text { sistemi }\end{array}$ & $\begin{array}{l}\text { Otomatik } \\
\text { depo ağı }\end{array}$ & zinciri depo & $\begin{array}{c}\text { Tedarik } \\
\text { zincirinde } \\
\text { depolamanın } \\
\text { olmaması }\end{array}$ \\
\hline
\end{tabular}




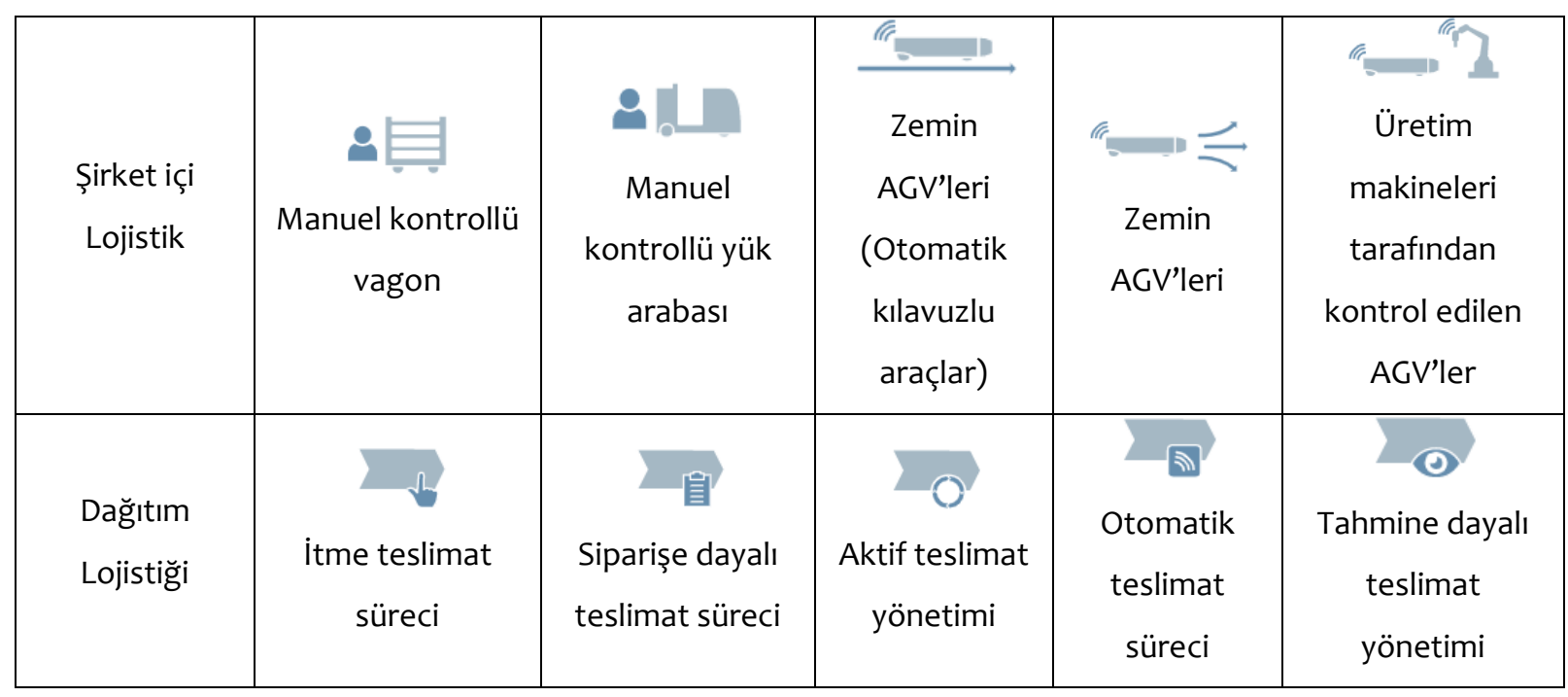

Şekil 4. Lojistik'in gelişme seviyeleri (Unity Consulting \& Innovation, 2016:13)

\section{Lojistik 4.0’'ın İçerisinde Yer Alan Önemli Kavramlar}

DHL Trend Research, 2016 yılında yayınlamış olduğu Lojistik Trend Radar isimli raporda sosyal, işletme ve teknoloji trendlerinin gelişimi üzerine odaklanmıştır. Lojistik trendleri Şekil 5.'te detaylandırılmıştır. Çalışmada bu trendlerin teknoloji alanında yakın gelecekte en uygulanabilir olanlarına odaklanılmıştır.

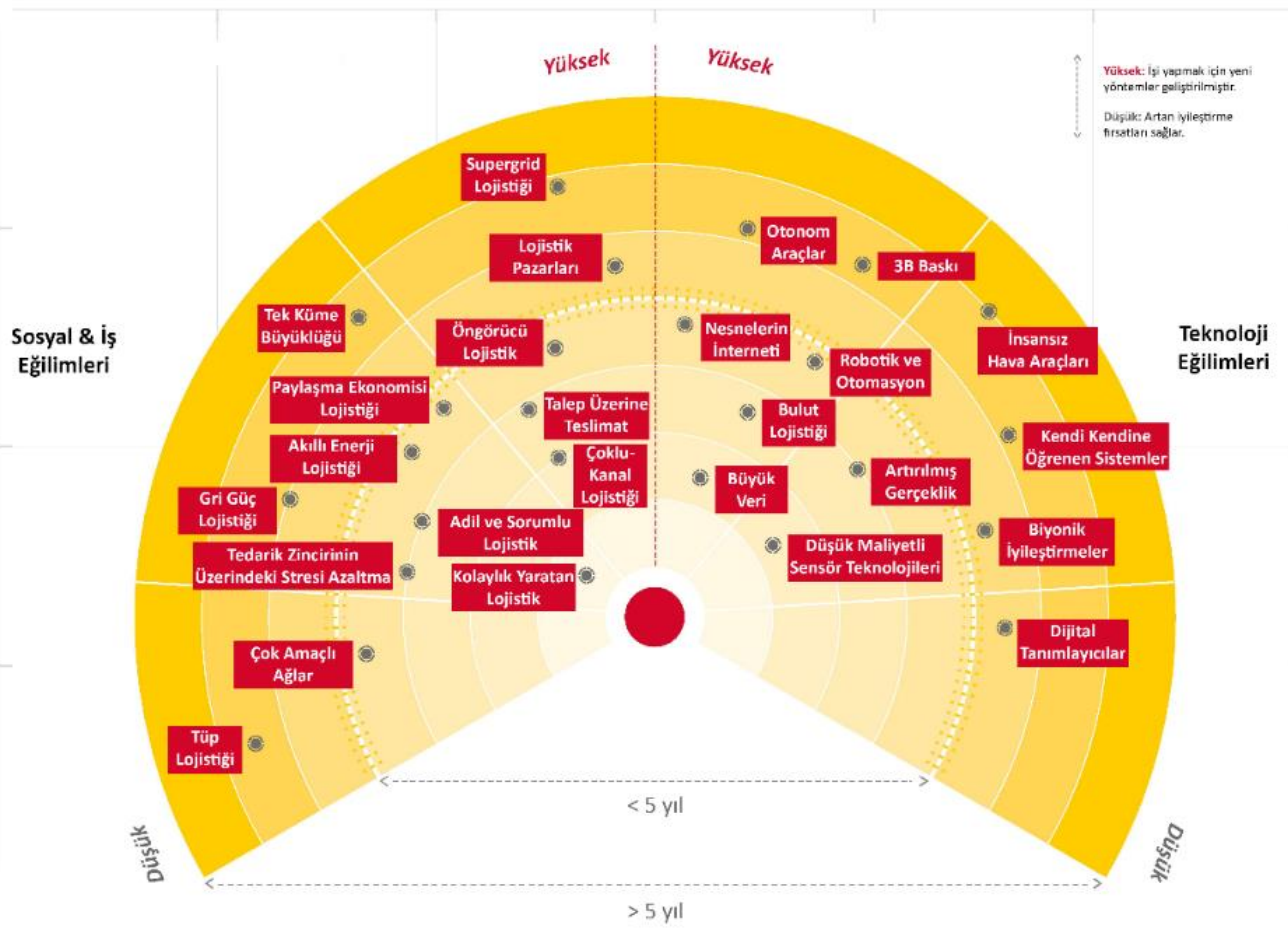

Şekil 5. Lojistik trend radarı (Bubner, Bodenbenner and Noronha, 2016: 14-15) 


\section{Nesnelerin İnterneti}

Nesnelerin interneti fikri, bir İngiliz girişimci ve melek yatırımcı olan Kevin Ashton tarafından ortaya atılmıştır. Fikir, 1999 yılında malların bilgisayarlar ile sensörler yardımıyla iletişim kurarak veri alışverişi yapmasıdır. Bu fikrin ortaya atılmasından neredeyse on yıl sonra ise, dünyada ağa bağlı cihazların sayısı, dünya nüfus sayısını aşmıştır. Çok uluslu bir ağ teknolojileri şirketi olan Cisco’ya göre "Her şeyin İnterneti” olarak adlandırılan nesnelerin internetinin gerçek doğuşudur. Bu yaklaşıma göre sadece nesneler değil; süreçler, veriler, insanlar ve hatta hayvanların birbirleri ile sürekli ve kesintisiz iletişim içerisinde olduğu bir sistem hayata geçmiştir (Witkowski, 2017: 766).

Nesnelerin interneti, lojistik sektörü üzerinde önemli bir etkiye sebep olmuştur. Bu kavram, üretim aşamasından başlayarak perakende aşamasına kadar küresel lojistik tedarik zincirinin her aşamasında birçok olumlu etkiye sahiptir. Bunlara örnek olarak tedarik zincirinin daha kolay izlenebilir olması, teslimatların gerçek zamanlı izlenmesi, verinin doğruluk olasılığının artması ve böylece daha hızlı bir istisna yönetimi sağlaması gösterilebilir (Tadejko, 2015: 56). Bunlara ilave olarak nesnelerin interneti alanındaki gelişmeler, otomatik iş hücreleri, taşıma sistemleri, lojistik ve depolama sistemleri gibi üretim ortamlarındaki çeşitli kablosuz sensör ağları uygulamalarının izlenmesine ve görselleştirilmesine olanak sağlar (Rocha et al., 2017:2).

\section{Siber-Fiziksel Sistem}

Siber-fiziksel sistem kavramı ilk olarak 2006 yılında Amerika Birleşik Devletleri’nde, fiziksel dünya ile bağlantılı bilgisayar sistemlerinin artan önemine vurgu yapmak için Lee tarafindan kullanılmıştır (Alçın, 2016: 23). Siber - fiziksel sistemler, operasyonların bir bilişimsel çekirdek yardımıyla birbirlerine entegre edildiği, izlendiği ve/veya kontrol edildiği fiziksel, biyolojik ve mühendislik sistemleridir (Loukas, 2015: 8). Diğer bir tanıma göre siber fiziksel sistemler, dönüşümcü araştırma yaklaşımları gömülü bilgisayar teknolojilerini fiziksel olgulara entegre eden karmaşık, çok disiplinli, fiziksel olarak duyarlı sistemlerdir (Gunes, Peter, Givargis and Vahid, 2014: 4242). Siber fiziksel sistemlerde fiziksel kısmını sensörler, aktüatörler ve donanımlar oluştururken, siber kısmını ise yazılım modülleri oluşturmaktadır. Siber fiziksel sistemlerde sensörler ve aktüatörler yardımıyla fiziksel işlemlerle ilgili bilgiler gerçek zamanlı olarak toplanır ve değişen koşullara ve çevreye uyum sağlamak için fiziksel sistemler üzerinde akıllı kontroller yapılabilir(Tu, Lim and Yang, 2018: 3). Siber fiziksel sistemlere bilgisayar ve ağ donanımlı tıbbi ekipmanlar, insanlı ve insansız araçlar, ev otomasyon sistemleri, ak1llı trafik yönetim sistemleri ve yeni nesil güç şebekeleri örnek olarak gösterilebilir (Loukas, 2015: 8). Siber Fiziksel Sistemler, tedarik zincirinin malzeme akışının tam şeffaflığı için yeni bir boyut sağlamaktadır. Böylece, siber fiziksel sistem teknolojileri, ürünlerin izlenmesinde, tüm zincir elemanları için güvenlik sağlanmasında, bir veri iletişim ortak platformuna erişimde, talep, stok ve satış 
hakkında bilgi sağlanmasında ve üretim sırasındaki anomalileri tahmin etmede kullanılabilir (Frazzon et al., 2015).

\section{Büyük Veri ve Veri Analitiği}

Büyük veri; 21. yüzyılın altını olarak adlandırılmaktadır. Büyük veri, geleneksel uygulamalar ve analizlerle analiz edilmesi ve kullanılması zor olan karmaşık ve yapısal olmayan verileri ifade eder. Büyük veri, lojistik ve tedarik zinciri yönetiminde yaygın olarak kullanılan izleme ve sensör cihazları, mobil cihazlar, nesnelerin interneti ve radyo frekansı tanımlama (RFID) teknolojisi ile ilgili çeşitli kaynaklardan gelmektedir (Papadopoulos, Gunasekaran, Dubey and Balta, 2017: 108).

Verinin, değer ve rekabet avantajı elde etmek amacıyla lojistik hizmet sağlayıcıları tarafindan ne şekilde kullanılması gerektiğinin bilinmesi, lojistik hizmet sağlayıcısının geleceğini önemli derecede ilgilendirmektedir. Büyük veri, günümüzde lojistik süreçleri iç içe bir kavramdır. Hızla büyüyen çevrimiçi ticaret nedeniyle daha karmaşık tedarik zincirleri oluşmakta ve bundan dolayı veri hacmi gün geçtikte daha da artmaktadır.

Günümüzde veri hacminin $\% 85$ 'i şirketler tarafından üretilmekle beraber, bu hacmin büyük bir kısmı ise lojistik faaliyetler esnasında üretilmektedir. Lojistik faaliyetlerdeki her hareket, sonrasında verimli bir şekilde analiz edilmesi gereken verileri yaratmaktadır. Doğru yapılan her analiz, lojistik süreçlerin optimizasyonu anlamına gelmektedir (Schmortte, 2016: 2).

\section{Bulut Lojistiği}

Günümüzde dijitalleşme çağında bulut bilişim her yerde mevcuttur ve bulut bilişim sayesinde iş dünyasının çeşitli sektörlerinde dijital dönüşümün hızı gün geçtikçe artmıştır. Lojistik sektörü, tedarik zinciri boyunca bütünleştirilmesi gereken birçok aktörden oluşmaktadır (Gomez, Grand and Grivas, 2015: 4). İşte bu noktada bulut bilişim, bilgi teknolojileri kaynaklarıyla (donanım, yazılım ve veri havuzları) büyük sermaye harcamaları olmaksızın birçok lojistik kuruluşun işbirliğini sağlar ve güçlendirir. Bulut bilişim hizmeti, lojistikte küresel görünürlük sağlamaktadır. Verilere ve hizmetlere her an her yerde erişebilmek için bu merkezi bulut hizmet vermektedir. Lojistik için bulut mimarisi, elle yapılan işlemlerin otomasyonu ile birlikte zaman ve maliyeti azaltımış ve verimliliği artırmıştır (Niharika and Ritu, 2015: 420).

Bulut lojistiği, bilgi teknolojileri kaynaklarının ve ilgili hizmetlerin, bir buluttan dış kaynak kullanımını sağlar. Bunun yanında birden çok kullanıcı tarafından oluşturulan ve kullanılan verilerin entegrasyonunu, eşitlenmesini ve paylaşımını sağlar. Ürün ve hizmet teklifleri ve talepleri için bir pazar alanı platformu gibi hareket eder. Ayrıca çok sayıda iş ortağının kolektif iş faaliyetlerinin yönetimini ve optimizasyonunu sağlar (Arnold, Oberländer and Schwarzbach, 2013: 1057). 


\section{Boyutlu Yazıcılar}

Endüstri 4.0 bağlamındaki gelişmelere ek olarak, tedarik zinciri ve lojistik süreçlerinin gelecekteki tasarımı, gelecek nesil üretim teknolojilerinin artan kullanımı ile güçlü bir şekilde etkilenecek ve yeni iş süreçlerinin geliştirilmesi hızlanacaktır. Hızlı prototipleme teknolojisinden hareketle temelleri atılan ve 1980 'lerde geliştirilerek patenti alınan bilgisayar destekli üretim teknolojilerinden biri olan üç boyutlu yazıcılar, günümüzde birçok iş sektöründe yaygın olarak kullanılmaya başlanmıştır (Hakan Verdu Martinez ve Can, 2016: 1).

Lojistik; doğru malzemenin, doğru miktarda, doğru durumda, doğru yerde, doğru zamanda, doğru tüketiciye, doğru fiyatla ulaşması olarak tanımlanabilir. Bu tanıma dayanarak 3 boyutlu yazıcılar, lojistik ve tedarik zinciri faaliyetleri üzerinde önemli kazanımlar sağlayacaktır (Wieczorek, 2017: 444). 3 boyutlu yazıcıların kullanımı, kişi ve kurumları bir lokasyona bağlı kalmasının önüne geçmiştir ve bu sayede şirketler ürünlerini mobil üretim ekipmanlarıyla müşterilerine yakın bir lokasyonda üretim yapabilme kabiliyetine sahip olacaklardır. Bu durum son kilometre lojistiği üzerine olumlu etkiler yaratacaktır. 3 boyutlu yazıcıların diğer bir etkisi de yedek parça üretimi üzerine olacaktır. 3 boyutlu yazıcılarla yedek parça üretimi ihtiyaç anında gerçekleştirileceğinden yedek parçaların depolanmasının ve bunlara sermaye bağlanmasının önüne geçilecektir.

\section{Artırılmış Gerçeklik}

Artırılmış gerçeklik temelli sistemler, üç boyutlu grafik araçlarında oluşturulan modellerin içe aktarılmasını, sahnelerin oluşturulmasını, senaryoların oluşturulmasını ve çalıştırılmasını sağlar (Ginters and Martin-Gutierrez, 2013: 9). Lojistik sektörü, çalışanların karar vermelerinde yardımcı olabilmek, çalışma koşullarını iyileştirmek ve gerçek zamanlı bilgi alabilmelerini sağlamak için artırılmış gerçeklikten faydalanabilir.

Artırılmış gerçeklik, lojistik planlama ve lojistik faaliyetlerini yürütme aşamalarında lojistik sektörüne yeni bir bakış açısı sağlamıştır. Artırılmış gerçeklik temelli sistemler, lojistik endüstrisinde depolama operasyonlarında, taşımacılık optimizasyonunda, son kilometre teslimatta ve geliştirilmiş katma değerli hizmetlerde kullanılmaya başlanmıştır (Glockner, Jannek, Mahn and Theis, 2014: 13).

\section{Otonom (Özerk) Robotlar}

Otonom robotlar, insan müdahalesine ve etkileşimine sahip olmayan ve görevleri gerçekleştirmek için programlanan aygıtlardır. Giderek karmaşıklaşan çalışma alanlarında faaliyetler, yeni sensör sistemleri, yapay zeka yöntemleri ve bu sistemler için gerekli bilgisayar performansına sahip çok esnek ve bilişsel olarak güçlü robotlar tarafindan gerçekleştirilmektedir (Hohenstein and Wagner, 2017: 3).

Otonom robotlar, daha tutarlı kalite ve üretkenlik düzeylerine ulaşma ve insanların yapamayacağı, yapmaması gereken ya da yapmak istemediği görevleri yerine getirme yeteneğine 
sahiptirler. Otonom robotlar, farklı boyutlardaki ve ağırlıktaki malzemeleri insanlara kıyasla daha hızlı ve verimli bir şekilde test edebilir, seçebilir, paketleyebilir, sıralayabilir, kurabilir, denetleyebilir veya taşıyabilir (Fitzgerald and Quasney, 2017: 5). Bu özellikleriyle otonom robotlar taşımacılık, depolama, etiketleme, paketleme ve elleçleme gibi temel lojistik faaliyetlerinde yakın gelecekte sıkça karşımıza çıkacaktır.

\section{Sonuç}

Lojistik sektörü dijital dönüşüme her ne kadar geç kalmış olsa da Lojistik 4.0 kavramı literatürde yerini almıştır. Lojistik sektörü oyuncularının Lojistik 4.0 sürecinde tehditleri ve fırsatları araştırmak ve mevcut durumda güçlü ve zayıf yönleri arasında dengeyi iyi kurabilmesi için Lojistik 4.0 ve eğilimlerine odaklanmalı ve hangi eğilimlerin faaliyetlerini önce etkileyeceğini analiz etmelidir (Bamberger, Nansé, Schreiber and Zintel, 2017: 44). Lojistik 4.0'ın esneklik ve çok yönlülük açısından sağladığı faydalar, dördüncü sanayi devriminin kaçınılmaz olarak geleceğin lojistiği üzerinde önemli bir etkiye sahip olacağını göstermektedir (ten Hompel und Kerner, 2015: 3). Lojistik, Endüstri 4.0'ın hızına hızlı bir şekilde adapte edilmeli ve bu sayede lojistik değer zincirinde hiçbir zayıf halka kalmamalıdır.

Yeni bilgi teknolojileri, dijitalleşme ve inovasyon için ideal koşulları yaratmakta ve lojistik sektöründe devrim niteliğindeki değişimlere yol açmaktadır. Müşteri taleplerindeki değişimler, ürün çeşitliliğindeki artışı, ürün teslimat sürelerindeki azalışı ve bunlara ait bilgilerin eşzamanlı olarak müşterilere aktarılması gerekliliğini beraberinde getirmiştir. Sonuç olarak, tüm tedarik zinciri boyunca optimizasyonlara gereksinim duyulmakta ve süreçlerin optimizasyonu da giderek karmaşıklaşmaktadır. $\mathrm{Bu}$ karmaşıklıklara yönelik çözümler, daha çok bilgi teknolojisi tabanlı ve yeni uygulamaların, platformların ve hizmetlerin geliştirilmesiyle mümkün olacaktır.

Lojistik 4.0 sistemleri, günümüzün mevcut kurumsal yapılarında değişikliğe sebep olur ve lojistik ve tedarik zinciri sürecine dahil olan tüm lojistik hizmet sağlayıcılarının düşüncesinde ve işleyişinde değişiklik yapılmasını gerektirir. Bunun yanı sıra, lojistik hizmet sağlayıcılarının güvenilir ve işbirliğine dayalı iş modellerine olan istekliliği dijital değişim ve dönüşüm için önemlidir. 


\section{Kaynakça}
$\mathbf{A B}$
Bakanlığı
(2018)
"Sanayi
4.0
Bilgi
Notu”,

https://www.ab.gov.tr/siteimages/resimler/Sanayi\%204_0\%20web.pdf [Erişim Tarihi: 05.06.2018]

Akinlar, Sevket (2014) "Logistics 4.0 and Challenges for the Supply Chain Planning and IT", https://www.iis.fraunhofer.de/content/dam/iis/tr/Session\%203_5_Logistics_Fraunhofer\%20IML_Akinlar.pdf [Erişim Tarihi: 05.06.2018]

Alçın, Sinan (2016) “Üretim İçin Yeni Bir İzlek: Sanayi 4.0”, Journal of Life Economics, 3(2), ss. 19-30.

Arnold, Uwe, Jan Oberländer and Björn Schwarzbach (2013) "Advancements in Cloud Computing for Logistics" [Proceeding], 2013 Federated Conference on Computer Science and Information Systems, 8-11 September, Kraków, pp. 1055-1062.

Bamberger, Vincent, Florent Nansé, Bernd Schreiber and Michael Zintel (2017) "Logistics 4.0 - Facing Digitalization-driven Disruption", Prism, 1, pp. 38-50.

Barreto, Luis, Antonio Amaral and Teresa Pereira (2017) "Industry 4.0 Implications in Logistics: An Overview", Procedia Manufacturing, 13, pp. 1245-1252. doi:10.1016/j.promfg.2017.09.045

Bubner, Nikolaus., Philipp Bodenbenner and Joseph Noronha (2016) Logistics Trend Radar, DHL Customer Solutions \& Innovation Research Report, Troisdorf.

Bulut, Ela ve Taner Akçacı (2017) "Endüstri 4.0 ve İnovasyon Göstergeleri Kapsamında Türkiye Analizi", ASSAM Uluslararası Hakemli Dergi, 4 (7), ss. 55-77.

Czaja, Frank (2016) Auswirkungen von Logistik 4.0 auf Mittelstand und Handwerk, SRH Hamm Research Report, Hamm.

Fitzgerald, Joseph and Evan Quasney (2017) Using Autonomous Robots to Drive Supply Chain Innovation, Deloitte Research Report, New York.

Frazzon, Enzo Morosini, Lucas Souza Silva and Paula Andrea Hurtado (2015) "Synchronizing and improving supply chains through the application of cyber-physical systems". IFAC-PapersOnLine, 48(3), pp. 2059-2064. doi: 10.1016/j.ifacol.2015.06.392

Ginters, Egils and Jorge Martin-Gutierrez (2013) "Low Cost Augmented Reality and RFID Application for Logistics Items Visualization”, Procedia Computer Science, 26, pp. 3-13. doi:10.1016/j.procs.2013.12.002

Glockner, Holger, Kai Jannek, Johannes Mahn and Björn Theis (2014) Augmented Reality in Logistics, DHL Customer Solutions \& Innovation Research Report, Troisdorf.

Gomez, Marisabel, Shanti Grand and Stella Gatziu Grivas (2015) "Digitalisation in Logistics and the Role of Cloud Computing", Logistics Innovation, 2, pp. 4-7.

Gunes, Volkan, Steffen Peter, Tony Givargis and Frank Vahid (2014) "A Survey on Concepts, Applications, and Challenges in Cyber-Physical Systems", KSII Transactions on Internet and Information Systems, 8(12), pp. 4242-4268. doi: 10.3837/tiis.2014.12.001

Hakan Verdu Martinez, Ezgi ve Emre Can (2016) "Bilgisayar Destekli Seramik Üretim Yöntemi Olarak Üç Boyutlu Yazıcılar ve Günümüz Koşullarında Uygulama Örneği”, Anadolu Üniversitesi Sanat \& Tasarım Dergisi, 6(1), ss. 1-15.

Hohenstein, Frank and Ole Wagner (2017) Robots in Picking Logistics, Miebach Consulting Research Report, München.

Işık, Fahri (2016) "Sanayi Devrimi İçin Geç Kalma Lüksümüz Bulunmuyor", Ekonomik Forum Dergisi, 259, s. 19, http://haber.tobb.org.tr/ekonomikforum/2016/259/016_027.pdf [Erişim Tarihi: 05.06.2018]

Jeschke, Sabina (2018), "Logistics 4.0 Do You Know Your Potential?, The Logistics 4.0 Maturity Benchmark Tool", http://www.smart-logistics-benchmark.com/en-gb [Erişim Tarihi: 05.06.2018]

Liao, Yongxin, Fernando Deschamps, Eduardo de Freitas Rocha Loures and Luiz Felipe Pierin Ramos (2017) "Past, Present and Future of Industry 4.0 - A Systematic Literature Review and Research Agenda Proposal", International Journal of Production Research, 55 (12), pp. 3609-3629. doi:10.1080/00207543.2017.1308576

Loukas, George (2015) Cyber-Physical Attacks: A Growing Invisible Threat, Elsevier, Oxford.

Lu, Yang (2017) "Industry 4.0: A Survey on Technologies, Applications and Open Research Issues", Journal of Industrial Information Integration, 6, pp. 1-10. doi: 10.1016/j.jii.2017.04.005

Niharika, Garg and Vijay Ritu (2015) "Cloud Architecture for the Logistics Business", Procedia Computer Science, 50, pp. 414-420. doi: 10.1016/j.procs.2015.04.013

Onozuka, Masashi (2015) Logistics 4.0 ー 物流ビジネスにおける新たなイノベーション, Roland Berger Research Report, Tokyo.

Ostadzadeh, S. Shervin, Fereidoon Shams and Kambiz Badie (2015) "An Architectural Model Framework to Improve Digital Ecosystems Interoperability", Elleity and Sobh (eds.) New Trends in Networking, Computing, Elearning, Systems Sciences, and Engineering, Springer International Publishing, Cham, pp. 513-520. doi:10.1007/978-3-319-06764-3_65

Özdemir, Aydın ve Mert Özgüner (2018) "Endüstri 4.0 ve Lojistik Sektörüne Etkileri: Lojistik 4.0”, Işsletme ve İktisat Çallşmaları Dergisi, 6(4), ss. 39-47. doi: 10.32479/iicd.147 
Öztemel, Ercan ve Samet Gürsev (2018) “Türkiye'de Lojistik Yönetiminde Endüstri 4.0 Etkileri ve Yatırım İmkanlarına Bakış Üzerine Anket Uygulaması", Marmara Fen Bilimleri Dergisi, 30(2), ss. 145-154. doi: 10.7240/marufbd.408560

Pamuk, Nurten Sinem ve Mehmet Soysal (2018) "Yeni Sanayi Devrimi Endüstri 4.0 Üzerine Bir İnceleme", Verimlilik Dergisi, (1), ss. 41-66.

Papadopoulos, Thanos, Angappa Gunasekaran, Rameshwar Dubey and Maria Balta (2017) "Big Data and RFID in Supply Chain and Logistics Management: A Review of the Literature and Applications for Data Driven Research", Chan et al. (eds) Supply Chain Management in the Big Data Era, IGI Global, Pennsylvania, pp. 108123. doi:10.4018/978-1-5225-0956-1.ch007

Rocha, Klayton Eduardo, Juliana Veiga Mendes, Luis Antonio de Santa-Eulalia and Virginia Aparecida da Silva Moris (2017). Adoption of IoT in Logistics \& Supply Chain Management: A systematic literature review. XXXVII Encontro Nacional de Engenharia de Produção "A Engenharia de Produção e as novas tecnologias produtivas: indústria, 4. doi: 10.14488/ENEGEP2017_TI_ST_238_379_32364

Saatçioğlu, Ömür Yaşar, Gökçe Tuğdemir Kök ve Nergis Özispa (2018) "Endüstri 4.0 ve Lojistik Sektörüne Yansımalarının Örnek Olay Kapsamında Değerlendirilmesi”, Süleyman Demirel Üniversitesi İktisadi ve İdari Bilimler Fakültesi Dergisi, (23), ss. 1675-1696.

Scherf, Jonas (2018) "Was ist Logistik 4.0? Alles zum Thema Digitalisierung \& Logistik", https://www.mmlogistik.vogel.de/was-ist-logistik-40-alles-zum-thema-digitalisierung-logistik-a-692722 [Erişim Tarihi: 05.06.2018]

Schiemann, Jörg (2016) Logistics 4.0 How Autonomous are Self-Managed Processes?, AXIT Research Report, Frankenthal.

Schlaepfer, Ralf C. and Markus Koch (2015) Industry 4.0 Challenges and Solutions for the Digital Transformation and Use of Exponential Technologies, Deloitte AG Research Report, Zurich.

Schmortte, Rebecca (2016) Logistics 4.0 - Smart, Connected, Digital, Ehrhardt + Partner Technical Article, Montabaur.

Schrauf, Stefan and Philipp Berttram (2016) Industry 4.0 How Digitization Makes The Supply Chain More Efficient, Agile, and Customer-Focused, Strategy\&, PwC Research Report, Munich.

Sener, Semih ve Birol Elevli (2017) “Endüstri 4.0’da Yeni İş Kolları ve Yüksek Öğrenim”, Mühendis Beyinler Dergisi, 1 (2), ss. 25-37.

Tadejko, Pawel (2015) “Application of Internet of Things in Logistics - Current Challenges, International Society for Manufacturing”, Service and Management Engineering, 7(4), pp. 54-64. doi:10.12846/j.em.2015.04.07

ten Hompel, Michael und Sören Kerner (2015) "Logistik 4.0 Die Vision vom Internet der autonomen Dinge", Informatik-Spektrum, 38(3), pp. 176-182. doi: 10.1007/s00287-015-0876-y

Tu, Mengru, Ming K. Lim and Ming-Fang Yang (2018) "IoT-Based Production Logistics and Supply Chain System - Part 2: IoT-Based Cyber-Physical System: A Framework and Evaluation," Industrial Management \& Data Systems, 118(1), pp. 96-125. doi: 10.1108/IMDS-11-2016-0504

Unity Consulting \& Innovation (2016) Supply Chain Management Strategy, Control and Operations, Unity Consulting \& Innovation Research Report, Hamburg.

Wang, Kesheng (2016) "Logistics 4.0 Solution-New Challenges and Opportunities" [Proceeding], 6th International Workshop of Advanced Manufacturing and Automation, 10-11 November, Manchester. doi:10.2991/iwama-16.2016.13

Wieczorek, Adam (2017) "Impact of 3D Printing On Logistics", Research in Logistics \& Production, 7(5), pp. 443-450. doi:10.21008/j.2083-4950.2017.7.5.5

Witkowski, Krzysztof (2017) "Internet of Things, Big Data, Industry 4.0 - Innovative Solutions in Logistics and Supply Chains Management”, Procedia Engineering, 182, pp. 763-769. doi:10.1016/j.proeng.2017.03.197 